\title{
Recurrent invasive lobular breast carcinoma presenting as gastric outlet obstruction
}

\author{
Alberto Contreras*1, Alejandro Robles ${ }^{1}$, Antonio Mendoza-Ladd ${ }^{2}$ \\ ${ }^{1}$ Department of Internal Medicine, Texas Tech University Health Sciences Center, El Paso, Texas, United States \\ ${ }^{2}$ Division of Gastroenterology, Texas Tech University Health Sciences Center, El Paso, Texas, United States
}

Received: March 18, 2019

DOI: $10.5430 /$ crim.v6n $3 p 26$
Accepted: June 12, 2019

Online Published: August 27, 2019

\begin{abstract}
Breast cancer is the most common malignancy in women. Metastatic disease is usually found in the bones, lungs, regional lymph nodes, liver, and brain. Metastases to the gastrointestinal tract occur in less than $1 \%$ of cases. We report an unusual case of metastatic invasive lobular carcinoma presenting as gastric outlet obstruction seven years after the initial diagnosis. To our knowledge, this is the first time that endoscopic ultrasound with fine-needle aspiration is used to establish a definite diagnosis of recurrent invasive lobular carcinoma to the gastrointestinal tract causing gastric outlet obstruction.
\end{abstract}

Key Words: Gastric outlet obstruction, Invasive lobular carcinoma, Breast cancer, Metastasis, Gastrointestinal tract

\section{INTRODUCTION}

Breast cancer is the most common malignancy and the second leading cause of cancer-related death among women. In the United States alone, approximately 266,000 new cases were diagnosed in 2018. ${ }^{[1]}$ About $5 \%$ of women present with metastatic disease at the time of diagnosis; while $30 \%$ will ultimately develop metastatic lesions later in the course of the disease. ${ }^{[2,3]}$ Breast cancer commonly metastasizes to the bones, lungs, regional lymph nodes, liver, and brain. ${ }^{[4]}$ Metastases to the gastrointestinal (GI) tract are rare and occur in less than $1 \%$ of cases. ${ }^{[5,6]}$ In those with metastasis to the stomach, over $60 \%$ were found to have co-existing metastasis to other organs. ${ }^{[7]}$ We report an unusual case of metastatic invasive lobular carcinoma (ILC) presenting as gastric outlet obstruction (GOO) seven years after the initial diagnosis.

\section{Case presentation}

The patient was a 58-year-old woman with a history of right breast ILC (T2N1M0 and ER/PR positive - stage IIB) di- agnosed in 2011. Staging imaging, including CT scan of the chest, abdomen, pelvis, and bone scan, did not reveal additional lesions. At that time, she underwent modified radical mastectomy with axillary dissection, prophylactic left simple mastectomy, and adjuvant chemotherapy (doxorubicin/cyclophosphamide x 4 cycles and paclitaxel x 12 cycles) and radiation. After treatment completion, she continued anastrozole for maintenance therapy. Subsequent CT scans, until 2016, were negative for any metastases.

In 2018, she presented to the emergency department of an outside facility complaining of two weeks of progressively worsening nausea, vomiting, and abdominal discomfort. A CT scan revealed a severely distended stomach with a large amount of debris suspicious for GOO. An upper endoscopy was then obtained, which showed a large amount of food in the stomach, stenosis of the pylorus, and a single mucosal nodule (see Figure 1). A biopsy of the lesion was obtained, and pathological examination revealed benign mucosa. She was subsequently referred to our center for further evalu-

\footnotetext{
*Correspondence: Alberto Contreras; Email: alberto.contreras@ttuhsc.edu; Address: Department of Internal Medicine, Texas Tech University Health Sciences Center, 4800 Alberta Ave. El Paso, Texas 79905, Texas, United States.
} 
ation where she underwent a repeat upper endoscopy that revealed mild pyloric stenosis; and a CT scan that showed a moderately distended stomach with mural thickening of the antrum and no evidence of contrast passing into the duodenum (see Figure 2). Because of the high suspicion for an underlying malignancy, she underwent EUS with FNA. The endosonographic evaluation showed an unusual thickening of the pyloric wall and distortion of all its layers (see Figure 3). Tissue was obtained with a 25 -gauge Sharkcore fine needle biopsy (FNB) needle. Pathological examination of the tissue revealed the presence of atypical cells, which were immunohistochemically consistent with metastasis from the known primary ILC (see Figure 4 A-D). Soon after the endoscopy, her GOO resolved, likely secondary to dilation of the pyloric stenosis by the endoscope. She was then referred to oncology for further management. At the time of this case report, she was undergoing palliative chemotherapy for stage IV ILC.
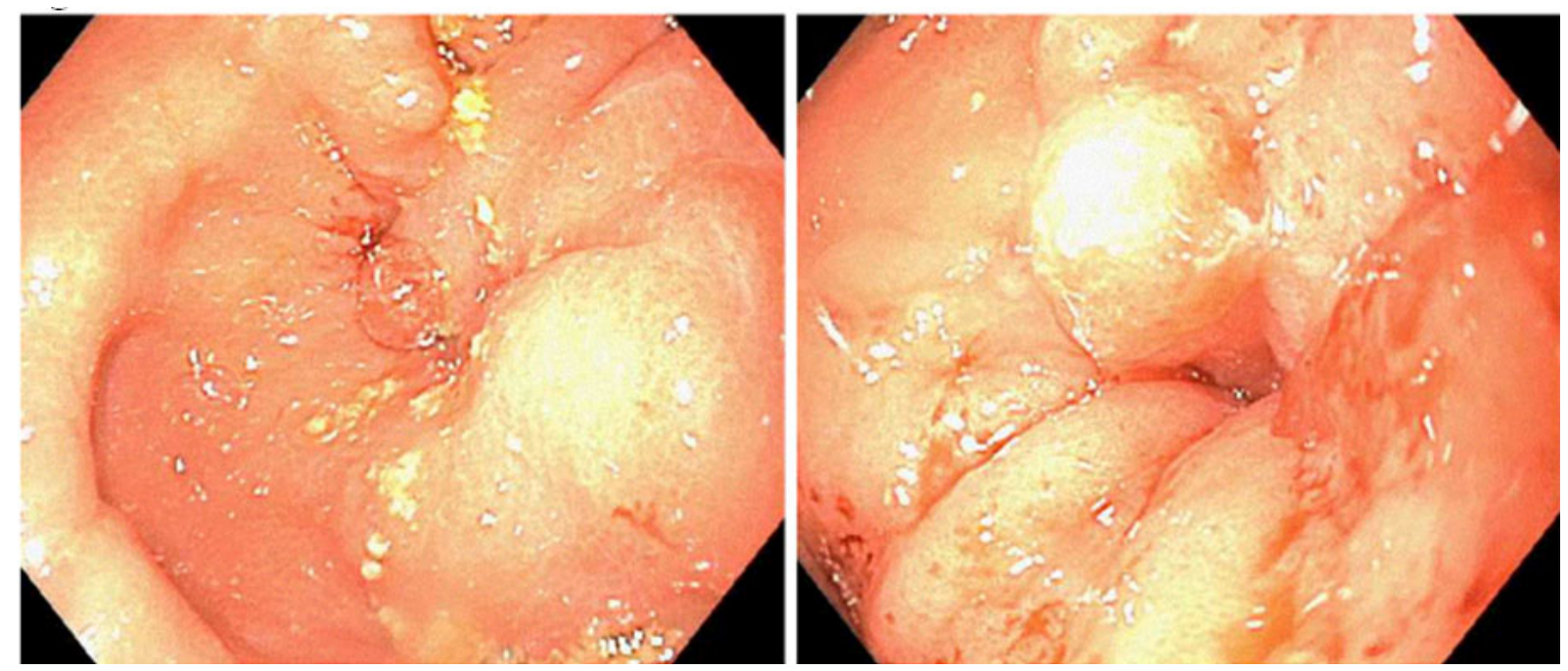

Figure 1. EGD showing severe gastric stenosis at the pylorus with a single mucosal nodule
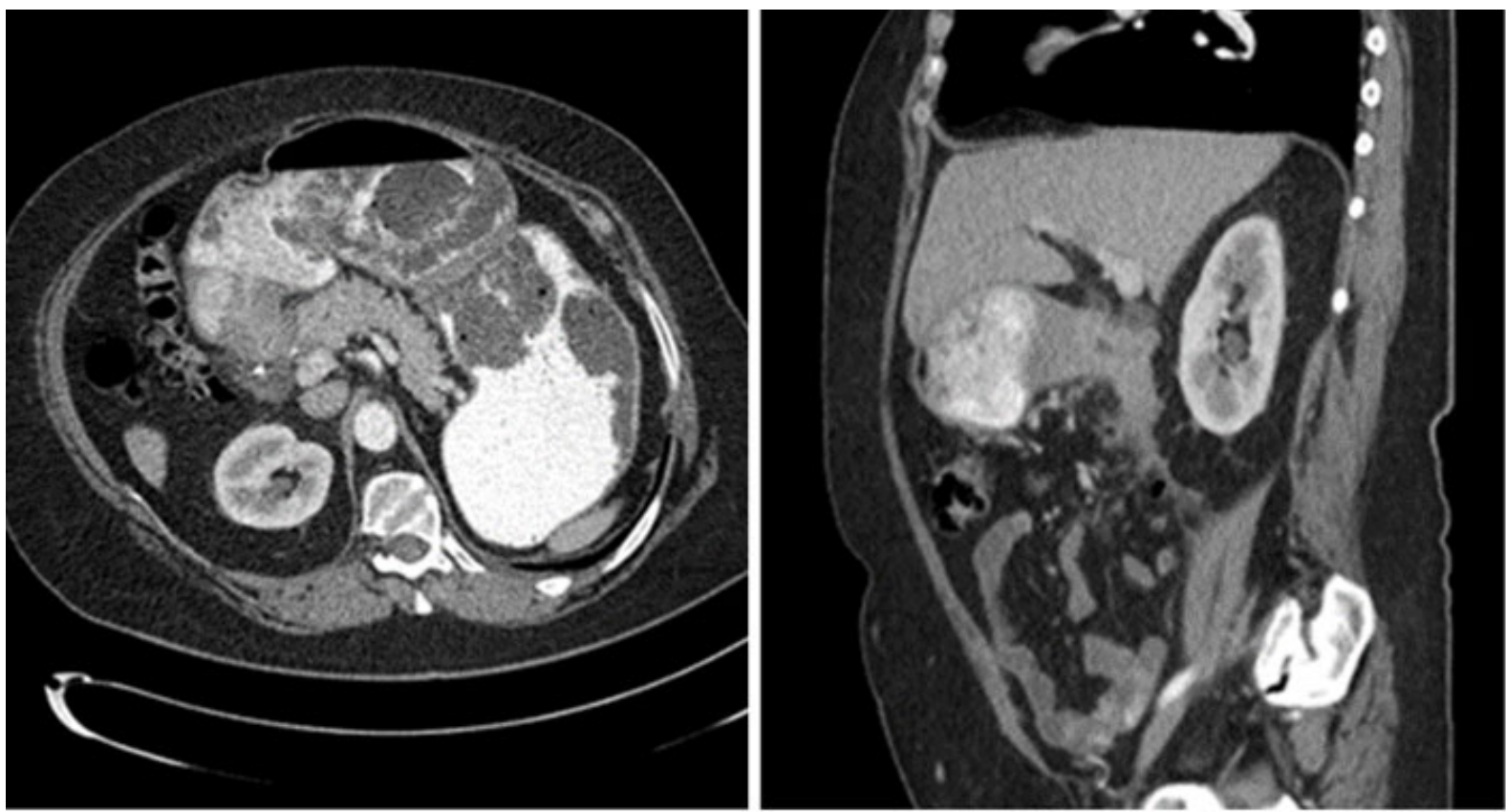

Figure 2. CT Abd/pelvis with contrast showing a moderately distended stomach, mural thickening at the antrum, and a contrast-filled antrum, without evidence of contrast passing through the pylorus 

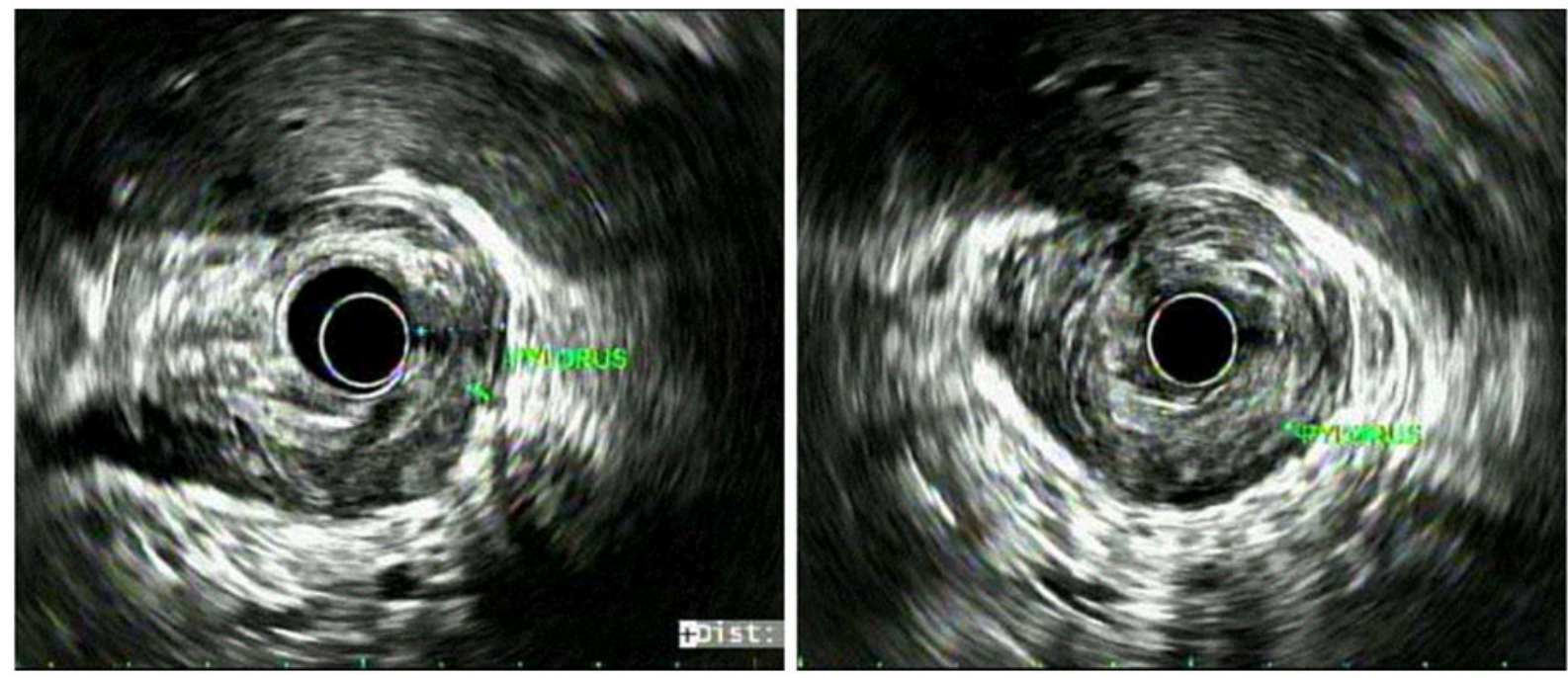

Figure 3. EUS showing a diffuse disproportional thickening of the pylorus wall with distortion of all the gastric wall layers. The total thickness is $1.8 \mathrm{~cm}$, and no well-delineated lesion is seen.

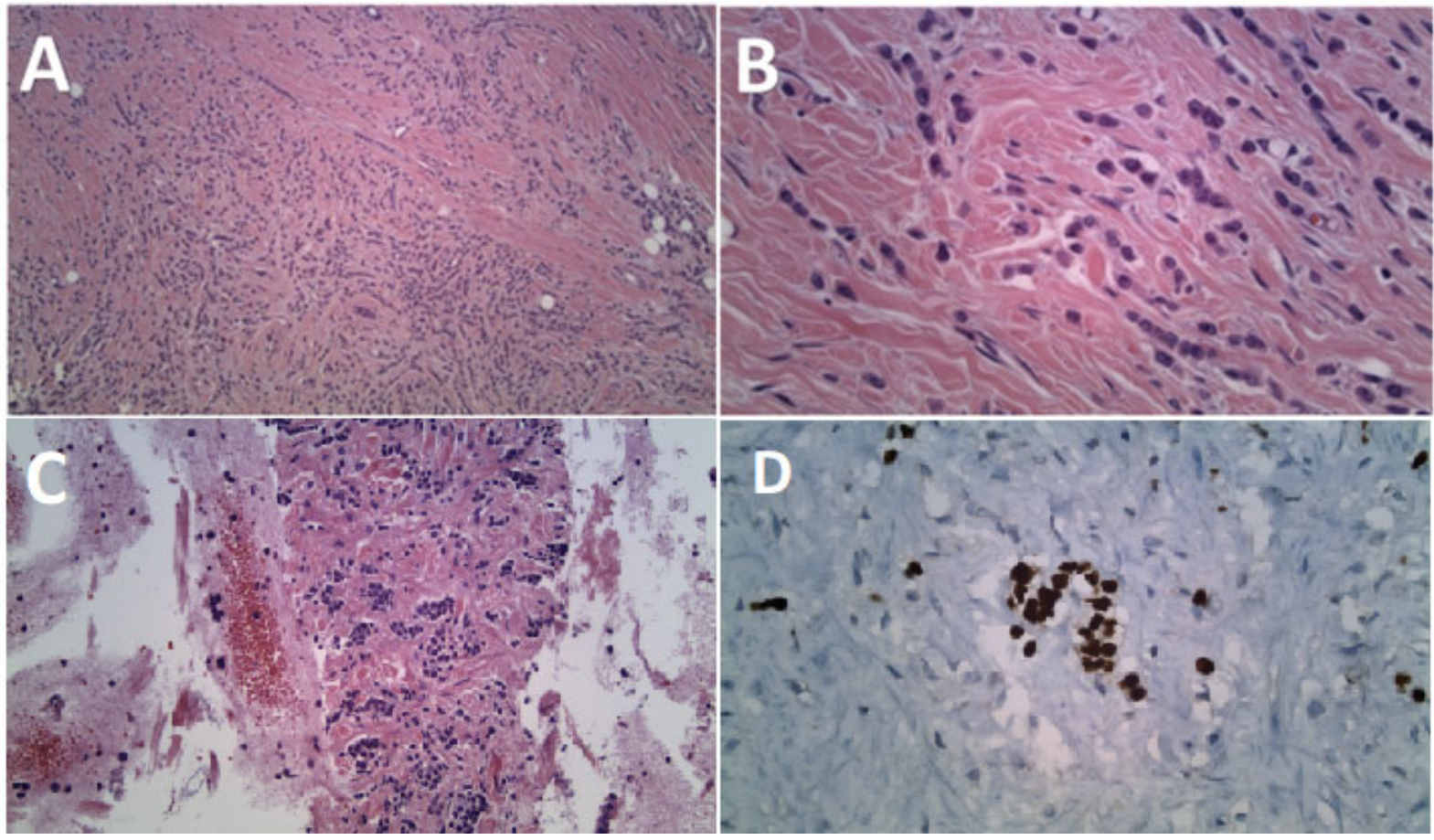

Figure 4. (A) Low power field view of breast tissue showing small round cells with surrounding fibrotic changes. (B) High power field view of breast tissue showing round cells in Indian file pattern, consistent with ILC. (C) Pyloric FNB showing small round uniform cells with a similar appearance to those previously seen in breast tissue. (D) Pyloric biopsy with positive GATA-3 immunostaining, consistent with metastatic disease from the known primary breast cancer.

\section{Discussion}

Gastric outlet obstruction is a clinical syndrome that results from any disease process that produces a mechanical obstacle to gastric emptying, and it is characterized by postprandial nausea, vomiting, and abdominal pain. ${ }^{[8]}$ Clinical entities that can result in GOO are generally categorized as being benign or malignant. Before the era of $\mathrm{H} 2$ blockers, the most common etiology was peptic ulcer disease; however, today greater than $50 \%$ of the cases are attributed to malignancy. ${ }^{[9]}$ The most common malignancies causing GOO are pancreatic and gastric adenocarcinomas and less commonly 
from lymphomas, ampullary carcinoma, and biliary tract cancers. ${ }^{[10]}$

Metastatic ILC is an uncommon cause of GOO, and only 6 cases have been reported ${ }^{[11-16]}$ (see Table 1). Although ILC accounts for approximately $10 \%$ of all breast cancers, it is this subtype that accounts for more than half of the reported cases of GI tract metastases. ${ }^{[17]}$

Table 1. Cases of breast cancer presenting as gastric outlet obstruction. ${ }^{[1-16]}$

\begin{tabular}{lccc}
\hline Report & Year & Age & $\begin{array}{l}\text { Time elapsed* } \\
\text { (months) }\end{array}$ \\
\hline $\begin{array}{l}\text { Hussain, Elahi, McManus, } \\
\text { et al. }\end{array}$ & 2012 & 65 & $* * *$ \\
$\begin{array}{l}\text { Kim, Shellenberger, Chen, } \\
\text { et al. }\end{array}$ & 2015 & 57 & $* * *$ \\
Nguyen, Le, Nguyen, et al. & 2009 & 44 & $* *$ \\
$\begin{array}{l}\text { Nodit, McGrath, \& Peel } \\
\begin{array}{l}\text { Ogawa, Namikawa, Oki, et } \\
\text { al. }\end{array}\end{array}$ & 2005 & 86 & 84 \\
$\begin{array}{l}\text { Weber, Decker, Puggioni, et } \\
\text { al. }\end{array}$ & 2001 & 52 & $* 8$ \\
\hline
\end{tabular}

Note.* Time elapsed from initial diagnosis of breast cancer to gastrointestinal metastasis, ** Gastrointestinal metastasis as the initial manifestation, ${ }^{* * *}$ Data not reported

The diagnosis of metastatic ILC, in this case, was initially elusive given the unusual presentation and the fact that the gastric mucosa at the pylorus appeared endoscopically normal. However, the clinical suspicion of malignancy was high in our differential. The combination of GOO in the setting of localized gastric wall thickening at the pylorus on CT scan, combined with no corresponding visible endoscopic abnormalities in this area, led us to suspect an infiltrating or malignant submucosal process. As reported in the literature, metastatic ILC presenting as GOO typically has a normal or relatively normal endoscopic appearance. Prompt utilization of EUS in our case was vital as it provided us with a mean to accurately delineate the gastric wall layers involved, as

\section{REFERENCES}

[1] Siegel RL, Miller KD, Jemal A. Cancer Statistics, 2018. CA Cancer J Clin. 2018; 68(1): 7-30. PMid:29313949. https ://doi . org/10 $.3322 /$ caac. 21442

[2] Schwartz RS, Erban JK. Timing of metastasis in breast cancer. N Engl J Med. 2017; 376(25): 2486-8. PMid:28636861. https: //doi.org/10.1056/NEJMcibr1701388

[3] Redig AJ, McAllister SS. Breast cancer as a systemic disease: a view of metastasis. J Intern Med. 2013; 274(2): 113-26. PMid: 23844915. https://doi.org/10.1111/joim.12084

Published by Sciedu Press well as to obtain tissue for histological analysis in a safe and effective manner. To our knowledge, this is the first time that EUS with FNA is used to establish a definite diagnosis of recurrent ILC, causing GOO.

Immediate treatment of GOO should be directed at relieving the obstruction and providing a route for enteral feedings. Effective endoscopic therapeutic options include enteral stent placement, and EUS directed gastrojejunostomy with a lumen apposing metal stent. Endoscopic gastrojejunostomy is a new technique, and studies comparing its outcomes to those of regular enteral stenting are not available yet. However, at least two studies suggest that it may have advantages over the conventional surgical gastrojejunostomy. ${ }^{[18,19]}$ If the above options are not available, a surgical gastrojejunostomy should be attempted. Finally, if no other way of relieving the obstruction is possible, gastro/nasojejunal tubes are acceptable options to maintain enteral intake.

\section{Discussion}

Metastatic breast cancer is an extremely rare cause of GOO. Despite the higher prevalence of invasive ductal subtype, it is the lobular type that most commonly metastasizes to the GI tract. Diagnosis of metastatic ILC to the GI tract is often tricky, given its non-specific symptoms and the prolonged disease-free interval before its presentation.

This case illustrates the importance of medical history when approaching a patient's current complaints. This patient presented with a relatively sudden onset of GOO symptoms and had a previous medical history of breast cancer. The high clinical suspicion of malignancy despite normal endoscopic findings led to the use of EUS as a way of safely and effectively obtaining tissue for accurate histological diagnosis. Clinicians should be aware that although rare, ILC can metastasize to the GI tract and cause GOO.

\section{CONFLICTS OF INTEREST Disclosure}

The author declares no conflict of interest
[4] Lee YT. Breast carcinoma: pattern of metastasis at autopsy. J Surg Oncol. 1983; 23(3): 175-80. PMid:6345937. https://doi.org/ $10.1002 /$ jso. 2930230311

[5] Rodrigues MV, Tercioti-Junior V, Lopes LR, et al. Breast cancer metastasis in the stomach: when the gastrectomy is indicated. Arq Bras Cir Dig. 2016; 29(2): 86-9. PMid:27438032. https: //doi.org/10.1590/0102-6720201600020005

[6] Ambroggi M, Stroppa EM, Mordenti P, et al. Metastatic breast cancer to the gastrointestinal tract: report of five cases and review of the literature. Int J Breast Cancer. 2012; 2012: 439023. PMid:23091732. https://doi.org/10.1155/2012/439023 
[7] Xu L, Liang S, Yan N, et al. Metastatic gastric cancer from breast carcinoma: A report of 78 cases. Oncology letters. 2017; 14(4): 4069-4077. PMid:28943914. https://doi.org/10.3892/ol.2 017.6703

[8] Cengiz E, Yildiz MK, Odabasi M, et al. Gastric outlet obstruction caused by focal nodular hyperplasia of the liver: a case report and literature review. Int J Surg Case Rep. 2013; 4(8): 681-3. PMid: 23792480. https://doi.org/10.1016/j.ijscr.2013.05.00 4

[9] Shone DN, Nikoomanesh P, Smith-Meek MM, et al. Malignancy is the most common cause of gastric outlet obstruction in the era of $\mathrm{H} 2$ blockers. Am J Gastroenterol. 1995; 90(10): 1769-70.

[10] Miyazaki Y, Takiguchi S, Takahashi T, et al. Treatment of gastric outlet obstruction that results from unresectable gastric cancer: current evidence. World J Gastrointest Endosc. 2016; 8(3): 165-72. PMid:26862366. https://doi.org/10.4253/wjge.v8.i3.165

[11] Hussain T, Elahi B, McManus MT, et al. Gastric obstruction secondary to metastatic breast cancer: a case report and literature review. J Med Case Rep. 2012; 6: 232. PMid:22870880. https : //doi.org/10.1186/1752-1947-6-232

[12] Kim AH, Shellenberger MJ, Chen ZM, et al. Case report of gastric outlet obstruction from metastatic lobular breast carcinoma. BMC Gastroenterol. 2015; 15: 120. PMid:26408025. https://doi.org/ 10.1186/s12876-015-0350-y

[13] Nguyen H, Le C, Nguyen H, et al. Gastric outlet obstruction as the presenting manifestation of metastatic lobular breast carcinoma. J Hosp Med. 2009; 4(9): E23-4. PMid:20013866. https ://doi.or $\mathrm{g} / 10.1002 / \mathrm{jhm} .479$
[14] Nodit L, McGrath K, Peel R. An 86-year-old woman with gastric outlet obstruction. Arch Pathol Lab Med. 2005; 129(10): 1349-51.

[15] Ogawa M, Namikawa T, Oki T, et al. Gastric outlet obstruction caused by metastatic tumor of the stomach originating from primary breast cancer: a case report. Mol Clin Oncol. 2018; 9(5): 523-6. PMid:3040223. https://doi.org/10.3892/mco.2018.1722

[16] Weber CA, Decker RA, Puggioni A, et al. Previously undiagnosed infiltrating lobular carcinoma of the breast presenting as a gastric outlet obstruction. Am J Gastroenterol. 2001; 96(12): 3475-7. PMid:11774997. https ://doi.org/10.1111/j.1572-0241. 20 $01.05369 . \mathrm{x}$

[17] Switzer N, Lim A, Du L, et al. Case series of 21 patients with extrahepatic metastatic lobular breast carcinoma to the gastrointestinal tract. Cancer Treat Commun. 2015; 3: 37-43. https: //doi.org/10.1016/j.ctrc.2014.11.006

[18] Perez-Miranda M, Tyberg A, Poletto D, et al. EUS-guided gastrojejunostomy versus laparoscopic gastrojejunostomy: an international collaborative study. J Clin Gastroenterol. 2017; 51(10): 896-9. PMid:28697151. https://doi.org/10.1097/MCG.0000000000 000887

[19] Khashab MA, Bukhari M, Baron TH, et al. International multicenter comparative trial of endoscopic ultrasonography-guided gastroenterostomy versus surgical gastrojejunostomy for the treatment of malignant gastric outlet obstruction. Endosc Int Open. 2017; 5(4): E275E281. PMid:28382326. https ://doi.org/10.1055/s-0043-1 01695 